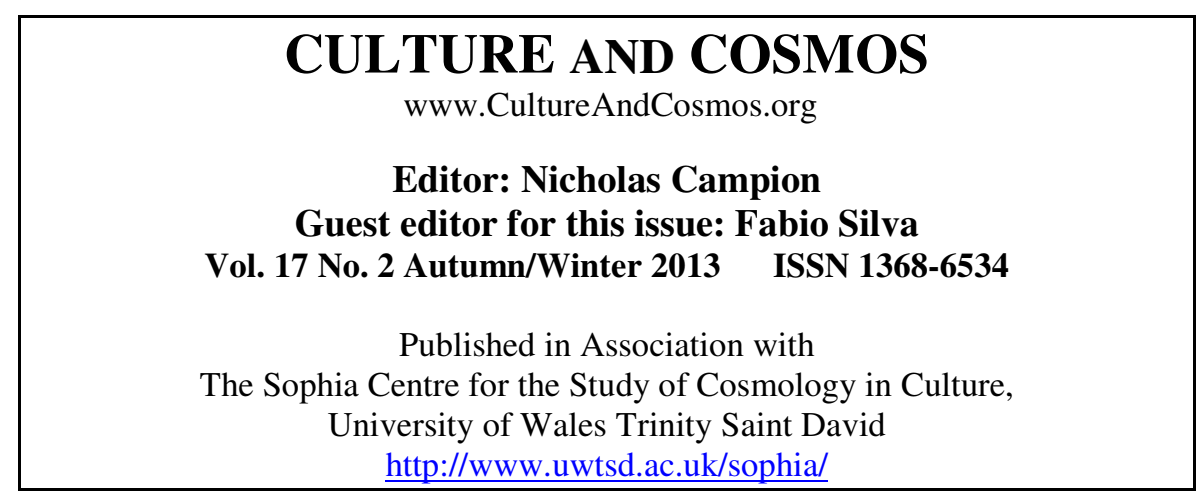

\title{
Editorial
}

\section{Landscape - Seascape - Skyscape}

This issue of Culture and Cosmos stems out of the 'Land, Sea and Sky: a "3-scape" approach to Archaeology' session of the 2013 meeting of the Theoretical Archaeology Group (TAG), at the University of Bournemouth. The session, which I organised, was intended 'to extend the discussion on Landscape and Seascape Archaeology, by considering their interaction with a third "-scape": the skyscape'. This was the second such session at a TAG meeting, the first of which occurred the previous year and resulted in the volume Skyscapes: The Role and Importance of the Sky in Archaeology. ${ }^{1}$

These sessions at TAG have been instrumental in bridging the gap between the fields of cultural astronomy and archaeology, bringing cutting edge archaeoastronomical work to the attention of archaeologists and viceversa. In this, they are part and parcel of a larger movement in British academia, with the University of Wales Trinity Saint David at its forefront. The School of Archaeology, History and Anthropology has recently put forward a five-year research plan based on the trinity of landscape, seascape and skyscape. The MA in Cultural Astronomy and Astrology has also incorporated this notion and retitled and revamped the Archaeoastronomy module, which from 2015 onwards will be known as 'Skyscapes, Cosmology and Archaeology'.

\footnotetext{
${ }^{1}$ Fabio Silva and Nicholas Campion (eds), Skyscapes: The Role and Importance of the Sky in Archaeology (Oxford: Oxbow Books, 2015).
} 
This issue opens with a theoretical discussion of how the trinity of land, sea and sky conspire to define place. Daniel Brown explores this and highlights its importance for the interpretation of archaeological sites with celestial alignments. He argues that one needs to explore archaeological structures not merely with recourse to statistical methods and plan views, as often happens, but to actually witness its context-the landscape, seascape and skyscape - that was 'witness and motivator to the erection of both monument and alignment'.

This is followed on by Pamela Armstrong who, in her contribution to this issue, asked the question of whether the material record of the Cotswold-Severn region displays evidence for a shift from lunar to solar symbolism at the Neolithic transition. Armstrong looks at a number of fully excavated structures that were built during this key prehistoric transition in search of the celestial alignments that are known to have featured in later monuments, such as Stonehenge and Avebury. Her findings reveal that, unlike the often made, overly simplistic assumptions of lunar or solar centric cosmologies, a 'more varied appreciation of the sky existed in those earliest of times'.

Looking further west into Pembrokeshire in southern Wales, Olwyn Pritchard identifies a pattern in the distribution of prehistoric monuments and settlements that suggests the possibility of a north-south transpeninsular route linking Carmarthen Bay, in the south, to Cardigan Bay, in the north. This route was marked, at its southern end, by the King's Quoit dolmen that the author had previously suggested was oriented northwards towards the lowest culmination of Deneb and Vega. The route then passes through several other monuments, including the Banc Du causewayed enclosure and associated monumental complex. Prehistoric Welsh sea, land and skies were thus linked in a unique way through what was surely a route of symbolic, if not ritual, significance.

The remaining two papers focus on human-made structures built on island settings. Firstly, Tore Lomsdalen discusses the islandscapes of the megalithic temples of the Maltese archipelago. These islands were only inhabited in late prehistory, presumably via Sicily, which implies a working knowledge of celestial navigation since the Maltese islands are too far out to be visible. A thousand years after arriving, these colonists developed one of the richest and most unique prehistoric cultures in the whole of Europe, with their vast megalithic temples and associated iconography. Lomsdalen discusses the role played by the sky, in association with the land and the sea, for this mysterious culture.

Culture and Cosmos 
Lastly, Fernando Pimenta and collaborators present preliminary work carried out among some structures in the Azores islands. These artificial structures have long been ignored by historians and archaeologists alike but have recently been featured in the debate surrounding a possible human presence in the archipelago predating the arrival of the Portuguese in 1432. Pimenta looks at the location and orientation of the pyramidal maroiços of Pico island as well as of three peculiar caves of Terceira Island, with respect to the surrounding landscape and skyscape. The findings suggest a symbolic element to these structures that goes beyond the purely functional previous interpretations, and justifying the need for further research and excavation.

Also featured in this issue are two book reviews, contributed by two other speakers at the TAG session. Liz Henty reviews Richard Bradley's The Idea of Order: The Circular Archetype in Prehistoric Europe, ${ }^{2}$ whereas Lionel Sims looks at Mike Parker Pearson's Stonehenge: Exploring The Greatest Stone Age Mystery. ${ }^{3}$ These are two works from distinguished archaeologists, authorities in their field, that cross-cut and correlate to each other in their ultimate goal of trying to understand why prehistoric Britons and Europeans went to the effort of building megalithic monuments.

The contributions to this issue demonstrate how the study of the celestial environment - the skyscape-complements the more traditional archaeological approaches to landscapes and seascapes, and how approaching this trinity holistically sheds further light into past societies, their beliefs and practices.

\section{Dr Fabio Silva Sophia Centre for the Study of Cosmology in Culture, School of Archaeology, History and Anthropology, University of Wales Trinity Saint David.}

\footnotetext{
${ }^{2}$ Richard Bradley, The Idea of Order: The Circular Archetype in Prehistoric Europe (Oxford: Oxford University Press, 2012).

${ }^{3}$ Mike Parker Pearson, Stonehenge: Exploring The Greatest Stone Age Mystery (London and New York: Simon \& Schuster, 2012).
} 